\title{
Particulate matter study at residential and educational areas in Shah Alam, Malaysia
}

\author{
Azyan Zafyrah Mohd Zahid, ${ }^{1, *}$, Nurul Najra Amizah Abdul Malik, and Jalina Kassim² \\ ${ }^{1}$ Faculty of Civil Engineering, Universiti Teknologi MARA Johor Branch, Pasir Gudang Campus, \\ 81750 Malaysia \\ ${ }^{2}$ Faculty of Civil Engineering, Universiti Teknologi MARA, Shah Alam, 51450 Malaysia
}

\begin{abstract}
Air pollution has become a crucial problem nowadays, especially on particulate matter. Major sources of particulate matter came from transportation, while wind speed, temperature and other factors can contribute to this problem. This research focuses on the determination of levels of particulate matter at residential and educational areas in Shah Alam. Two (2) sites were chosen, namely Flat Nilam Sari that represented the residential areas while University of Selangor represented the educational areas. Four (4) sets of levels of particulate matter and other parameters (traffic volume, temperature and wind speed) were obtained by using Dylos DC1700 Laser Particle Counters and Mini ThermoAnemometer respectively. The results obtained showed that the particulate matters $\left(\mathrm{PM}_{2.5}\right.$ and $\left.\mathrm{PM}_{10}\right)$ at both study areas are below permissible limits required by Malaysian Ambient Air Quality Guidelines (MAAQS). However, the Air Quality Indexes of $\mathrm{PM}_{2.5}$ at both study areas shows that the AQI readings are categorized as unhealthy. The highest AQI reading was 159 , which was recorded at residential area. In most cases, the results revealed that particulate matter produced by traffic vehicles has significant correlation with the increase of travelled particles. From the correlation analysis, both study areas have significant correlation of $\mathrm{PM}_{2.5}$ with medium vehicles while the educational area has correlation with all types of heavy, medium and small vehicles.
\end{abstract}

\section{Introduction}

The air that we breathe is critical to our survival. Air quality is directly linked to our health and standard of living. Excessive exposure to air pollution has been proven to be harmful to human health shown by the infamous case which happened in Donora in October 1948 where the pollutants were trapped in a valley for 5 days resulting in the death of 17 people and 5910 persons became ill [1]. These harmful air pollutants such as sulfur oxides and particulate matters became severe owing to the failure to notice anything strange with no method to measure pollution levels [2].

\footnotetext{
* Corresponding author: azyan8410@johor.uitm.edu.my
} 


\subsection{Particulate matter}

Air pollution occurs when the physical and chemical substances brought by natural processes or human activities resulting in the alteration and degradation of the quality of the air. According to the Clean Air Act of 1970 that established the National Ambient Air Quality Standard (NAAQS), there are six (6) major pollutants known as the 'criteria' of air pollutants, which includes the particulate matter $(\mathrm{PM})$, ozone $\left(\mathrm{O}_{3}\right)$, nitrogen oxides $\left(\mathrm{NO}_{\mathrm{x}}\right)$, carbon monoxide $(\mathrm{CO})$, sulphur dioxide $\left(\mathrm{SO}_{2}\right)$ and lead $(\mathrm{Pb})$. In this study, only one criterion was taken into consideration; particulate matter. Particulate matter is a mixture of solid particles and liquid droplets, also known as aerosol when it is suspended in the air. The presence of particulate matters in the atmosphere causes aesthetic and visibility problems. However, the excessive exposure to bad air quality is a major concern as it does not only results in adverse health effects to humans [3], but its content of numerous mixtures of organic and inorganic chemical compositions may also leads to harm to agricultural crops, forest species and ecosystems as well as the materials and artworks of the buildings $[4,5]$.

Particulate matter comes in various shapes and sizes, based on their potential to create health problems. Exposure to poor air which contains a widespread of particulate matter will result in serious health problems. The extremely small size of particulate matters increases the possibility of access to the human body compared to larger particles. The particles with 10 micrometers diameter or smaller may cause serious health effects as those sizes are able to pass through nose and throat. Once inhaled, the particles could affect the heart and lungs [6]. Other than inhalation, direct absorption through skin as well as consumption of contaminated food and water exposed to the excessive harmful air particles may also cause health effects to humans. According to [7], the exposure to particulate matter has inevitably increased to significant respiratory morbidity. A study in Beijing has reported that middle-aged non-smokers are unconditionally at excess risk of respiratory symptoms [8]. Children are unexceptional as outdoors activities and sports increased the potential on the development of asthma especially on children [9]. In Mexico City, [10] has proved that high ambient levels of particulate matter able to increase risk of asthma exacerbation among children. According to WHO report, 2 million children under the age of 5 dies every year as a result from acute respiratory diseases exacerbated by air pollution [11]. In several circumstances, the excessive exposure of particulate matter has demonstrated increased the cardiovascular and respiratory mortality [12]. In different cases, a study revealed that maternal exposure to particulate matter, $\mathrm{SO}_{2}$ or both are able to jeopardize and increase the risk of low birth weight [13]. Another study disclosed that air pollution may promote adverse health effects on fetuses by increased intrauterine mortality [14].

In general, there are many sources that contribute to the increase of air pollution problems. These sources are categorized into groups; natural sources and anthropogenic sources. The air pollution produced by natural sources includes erupted volcanoes, accidental fires in forestry, ashes storm, and road ashes. Meanwhile, the anthropogenic sources are commonly produced by emissions from industry factories, power stations, and industrial fuel burning [15]. Due to extensive sources of air pollutions, particulate matter may contain numerous different chemical elements. Over the past several years, particularly from July to October, uncontrolled open burning by the large-scale forest and plantation fires at a neighbour country has cause a serious haze event in Malaysia as the particulate matters have been transported by the southwesterly winds from Sumatra and Kalimantan. However, throughout non-haze period, vehicles emissions took highest percentage with $82 \%$ while the remaining percentage divided into power station $(9 \%)$, industrial fuel burning $(5 \%)$, industrial production processes $(3 \%)$, open burning $(0.8 \%)$, domestic and commercial furnaces $(0.2 \%)$ [16]. According to [15], transportation is mobile source that 
involves many different types of vehicles, engines and a variety of fuels that emits different simple and complex pollutant. [17] indicated that the impact of poor air quality below the troposphere was from the industry and road traffic.

Despite the urbanization transition throughout the whole world including Malaysia, air pollution is undeniably a crucial issue. Following the rapidly expanding economies, the expansion of urban population caused people to establish metropolitan cities as well as industries and the increasing number of vehicles used [18]. Vehicles have become a major contributor to air pollution as humans rely on these methods to move from one place to another. [19] has reported the number of vehicles registered in Malaysia is increased by $26 \%$ from 7.7 million in 1996 to 10.6 million in 2000 [20]. Road traffic emitted particulate matter that produced from braked lining, exhausted pipes, tyre wear and dust from the surface [21]. Considering the population growth and increase number of vehicles therefore the escalation of exposure to traffic-related air pollution. Exposure of carbon monoxides, nitrogen oxides and hydrocarbons emitted from the vehicles worsen as it is exposed to surrounding temperature and wind speed which disperses the pollutant in the air.

It is vital to keep particulate matter under control in order to protect public health and public welfare. On the surface, it seems that the rise of particulate matter at residential and educational areas is due to the high population at these places. In this study, the high concentration of people and vehicles near Flat Nilam Sari at Seksyen 7 that represents residential areas and University of Selangor, UNISEL at Seksyen 7 that represents educational areas contributed to the air pollution. Furthermore, both areas are located near to the main road. According to [21], the stop-start traffic released more pollution into air with increasing emission of particulate matter. The increase number of short journeys and traffic flow, together with increase in the number of diesel vehicles results in a pointedly higher amount of particulate matter [21]. Based on the observation, the traffic at these study areas were busy and the parking lots nearby were constantly occupied. Therefore, it emits more haze and hazardous particles. In Malaysia, the air pollution is at its peak during morning peak hour which mainly owing to vehicle emissions, whereas the late evening peak was mainly due to meteorological conditions [20, 22]. Referring to the subject matter, the morning and evening peak hours was determined based on mobility and the highest particulate matter recorded throughout sampling time.

This study attempts to determine the overall particulate matter levels in the air for these two study areas. Furthermore, this study aims to see whether the study areas comply with acceptable standards. Apart from that, other parameters (such as traffic volume, temperature and wind speed) are also being considered in this study to identify the likely possible relation between these parameters affecting the particulate matters. According to [2], deterioration in air quality occurs when the bigger firm particles passes through the air with great speed and this happens because of the presence humidity, temperature, daylight and location of uncovered material. [23] in their study stated that temperature and wind direction were two main factors that influence pollutant load. Therefore, the significance of this study is to determine the status of particulate matter levels $\left(\mathrm{PM}_{2.5}\right.$ and $\left.\mathrm{PM}_{10}\right)$ as well as to develop the trend pattern of data at both residential and educational areas. Lastly, the relationship between particulate matter with traffic volume, temperature and wind speed are established based on the data obtained. 


\section{Research methodology}

\subsection{Study area}

Shah Alam is the capital city of Selangor and a rapidly emerging area in Malaysia with many institutions of higher learning, residential areas, industrial and commercial areas. Two (2) sampling locations were selected. The first was located next to flat Nilam Sari and Jalan Persiaran Bestari at Seksyen 7 representing a residential area. Another selected sampling location was near University of Selangor, UNISEL as it represents an educational area.

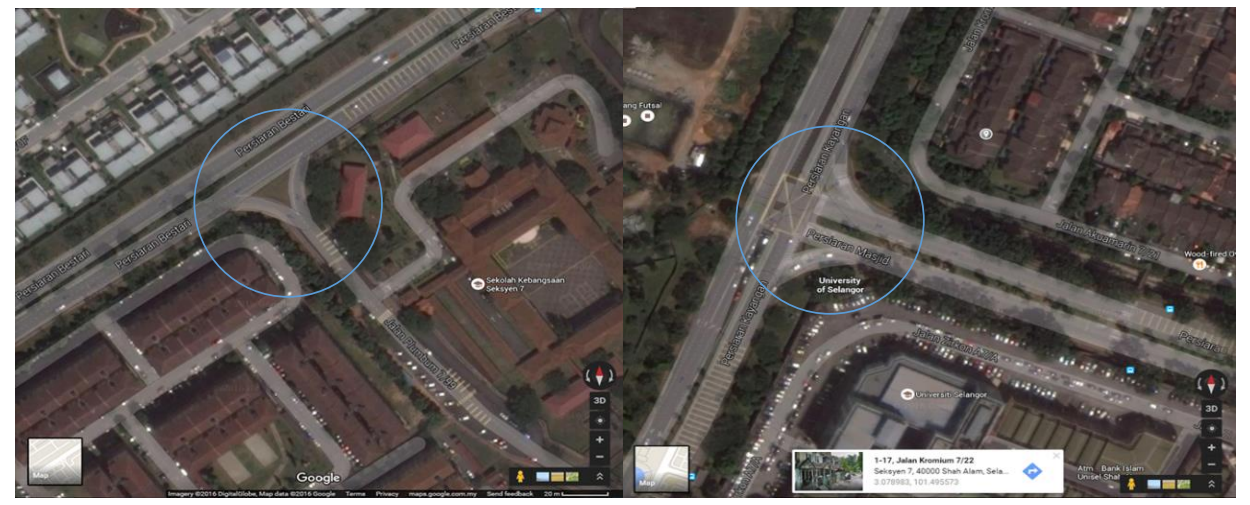

Fig. 1. Location for data collection next to Flat Nilam Sari and Jalan Persiaran Bestari at Seksyen 7 represents the residential area (left). Location for data collection near University of Selangor, UNISEL at Seksyen 7 the represents educational area (right).

\subsection{Measurement of PM, traffic volume, temperature and wind speed}

In this study, the observation of particulate matter, traffic volume, temperature, and wind speed was carried out in two (2) phases, during weekends and weekdays in the morning and evening. The observation for the first phase started from 8.00 a.m. until 9 a.m. while for the second phase, observation started from 5.00 p.m. until 6.00 p.m. The data was collected in ten (10) minutes intervals. These particular periods were selected considering the peak hour factor, where there is a lot of people and traffic movement.

\subsection{Data collection and statistical methods}

The type of the equipment that was used was the Dylos DC 1700 model which uses laser particle counters [24]. It counted individual particles, sizes small and large particles. The particle measurement was 0.5 and 2.5 micron. Mini Thermo-Anemometer was used to determine the air velocity or wind speed and temperature at the same time [25]. Counters were used to determine traffic volume at the study areas. Vehicles were classified into three (3) classes. The first class is for heavy vehicles such as lorries and buses. The second class is for medium vehicles such vans, cars and taxis while the third class is for small vehicles such bicycles and motorcycles. All data of particulate matter, traffic volume, temperature and wind speed were statistically analyzed by using Statistical Package for Social Sciences (SPSS) and Microsoft Excel. The trend patterns for particulate matter counter of the sampling location were developed. Lastly, the typical profiles of particulate matter with 
traffic volume, temperature and wind speed were established to study the relationship between these parameters.

Table 1 is the summary of sampling activities conducted on different days dated $12^{\text {th }}$ October 2016, and $15^{\text {th }}$ October 2016 near University of Selangor, UNISEL, and $16^{\text {th }}$ October 2016 and $17^{\text {th }}$ October 2016 near Flat Nilam Sari.

Table 1. Sampling Activities.

\begin{tabular}{|c|c|c|c|c|}
\hline \multirow[b]{2}{*}{ Date } & \multirow[b]{2}{*}{ Location } & \multicolumn{2}{|c|}{ Time } & \multirow[b]{2}{*}{ Remarks } \\
\hline & & $\begin{array}{l}8.00 \text { a.m. - } \\
9.00 \text { a.m. }\end{array}$ & $\begin{array}{c}5.00 \text { p.m. - } \\
6.00 \text { p.m. }\end{array}$ & \\
\hline $12^{\text {th }}$ Oct 2016 & $\begin{array}{c}\text { University of Selangor, } \\
\text { UNISEL }\end{array}$ & I & I & Weekday \\
\hline $15^{\text {th }}$ Oct 2016 & $\begin{array}{c}\text { University of Selangor, } \\
\text { UNISEL }\end{array}$ & I & I & Weekend \\
\hline $16^{\text {th }}$ Oct 2016 & Flat Nilam Sari & I & I & Weekend \\
\hline $17^{\text {th }}$ Oct 2016 & Flat Nilam Sari & l & l & Weekday \\
\hline
\end{tabular}

/ represents data recorded

These two (2) areas were chosen in this study to represent educational areas (near University of Selangor, UNISEL) and residential areas (near Flat Nilam Sari). Data was collected in two (2) phases for 2 days at each location. Each day represents weekend and weekday data. Data was recorded within ten (10) minute intervals for one (1) hour. Average particulate matter levels were used to analyze the result. Data for wind speed, temperature and traffic volume were also recorded to enable correlation with particulate matter level of 2.5 and 10 at study areas.

\section{Result and analysis}

\subsection{Status of Particulate Matter levels ( $\mathrm{PM}_{2.5}$ and $\left.\mathrm{PM}_{10}\right)$}

Table 2 shows a comparison of result of particulate matter reported in previous literature review and Malaysian Ambient Air Quality Guidelines (MAAQS). From the observation, the particulate matter $\left(\mathrm{PM}_{2.5}\right.$ and $\left.\mathrm{PM}_{10}\right)$ for both locations are below the permissible limit produced by MAAQS. Additionally, the status of air quality can also be measured with Air Quality Index (AQI) scale provided by the U.S Environmental Protection Agency. The AQI is measured for four major air pollutants regulated by the Clean Air Act including groundlevel ozone, particle pollution, carbon monoxide, and sulfur dioxide [6]. In this study, at residential area, $\mathrm{PM}_{2.5}$ observed a range between $40.25 \mu \mathrm{gm}^{-3}$ to $43.86 \mu \mathrm{gm}^{-3}$ while at educational area, the range observed was between $35.2 \mu \mathrm{gm}^{-3}$ to $37.1 \mu \mathrm{gm}^{-3}$. $\mathrm{PM}_{10}$ also had been observed with reading from $101.83 \mu \mathrm{gm}^{-3}$ to $102.47 \mu \mathrm{gm}^{-3}$ and from $80.20 \mu \mathrm{gm}^{-3}$ to $91.50 \mathrm{\mu gm}^{-3}$ for residential and educational areas respectively. 
Table 2. Comparison of Particulate Matter between obtained result and established result in previous literatures.

\begin{tabular}{|c|c|c|c|c|c|}
\hline & $\begin{array}{c}\mathrm{PM}_{2.5} \\
(\mathrm{range}) \\
\left(\mu \mathrm{gm}^{-3}\right)\end{array}$ & $\begin{array}{c}\mathrm{PM}_{10} \\
(\mathrm{range}) \\
\left(\mu \mathrm{gm}^{-3}\right)\end{array}$ & $\begin{array}{c}\mathrm{PM}_{2.5} \\
\mathrm{LR}^{*} \\
\left(\mu \mathrm{gm}^{-3}\right)\end{array}$ & $\begin{array}{c}\mathrm{PM}_{10} \\
\mathrm{LR}^{*} \\
\left(\mu \mathrm{gm}^{-3}\right)\end{array}$ & $\begin{array}{c}\text { MAAQS } \\
\text { permissible limit } \\
\left(\mu \mathrm{gm}^{-3}\right)\end{array}$ \\
\hline $\begin{array}{c}\text { Residential } \\
\text { area }\end{array}$ & $\begin{array}{c}40.25- \\
43.86\end{array}$ & $\begin{array}{c}101.83- \\
102.47\end{array}$ & $\begin{array}{c}48.00- \\
52.40[26]\end{array}$ & $\begin{array}{c}68.20- \\
96.30[26]\end{array}$ & $\begin{array}{c}75\left(\mathrm{PM}_{2.5}\right) \\
{[27]}\end{array}$ \\
\hline $\begin{array}{c}\text { Educational } \\
\text { area }\end{array}$ & $\begin{array}{c}35.20- \\
37.10\end{array}$ & $\begin{array}{c}80.20- \\
91.50\end{array}$ & $26.00[28]$ & $34.00[28]$ & $\begin{array}{c}150\left(\mathrm{PM}_{10}\right) \\
{[27]}\end{array}$ \\
\hline
\end{tabular}

LR* Comparison to previous literature review

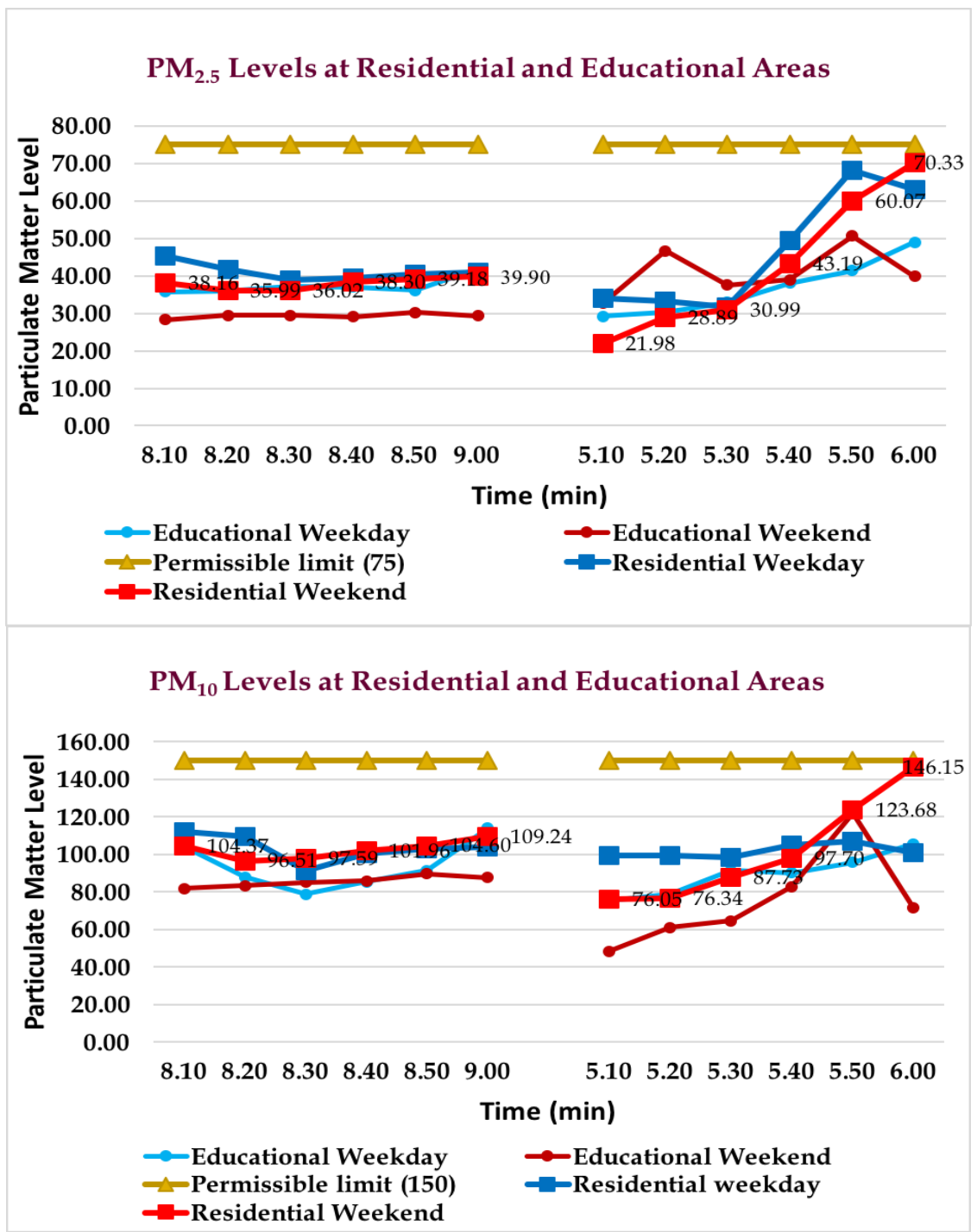

Fig. 2. $\mathrm{PM}_{2.5}$ and $\mathrm{PM}_{10}$ levels at residential and educational areas on weekdays and weekends. 


\subsection{Air Quality Index}

Table 3 shows the status of air quality at the study areas. From this study, the air quality index (AQI) of $\mathrm{PM}_{2.5}$ at residential area is categorized as unhealthy, while it is especially unhealthy for sensitive groups at educational area. The residential area recorded the highest AQI reading with 159. According to [6], this category may affect sensitive groups including people with respiratory or heart disease, primarily among elderly and kids, who are at greater risk as they may experience health effects such as increased aggravation of heart or lung disease.

Likewise, the AQIs of $\mathrm{PM}_{10}$ at both residential and educational areas are categorized as moderate. The highest AQI reading is 96 , which was recorded at residential areas. This level is acceptable; however, it still results in a high risk to people who have respiratory diseases. Normally people who are sensitive should consider reducing prolonged or heavy exertion [6].

Table 3. Status of air quality and level of health concern at residential and educational areas according to [6].

\begin{tabular}{|c|c|c|c|}
\hline Location & $\begin{array}{c}\text { Particulate } \\
\text { Matter }\end{array}$ & AQI Value & $\begin{array}{c}\text { Level Of Health } \\
\text { Concern }\end{array}$ \\
\hline \multirow{2}{*}{ Residential Area } & $\mathrm{PM}_{2.5}$ & 159 & Unhealthy \\
\cline { 2 - 4 } & $\mathrm{PM}_{10}$ & 96 & Moderate \\
\hline \multirow{2}{*}{ Educational Area } & $\mathrm{PM}_{2.5}$ & 138 & $\begin{array}{c}\text { Unhealthy for } \\
\text { Sensitive Group }\end{array}$ \\
\cline { 2 - 4 } & $\mathrm{PM}_{10}$ & 84 & Moderate \\
\hline
\end{tabular}

\subsection{Trend Pattern Of Data At Residential And Educational Area}

\subsubsection{Residential Area (near Flat Nilam Sari, Seksyen 7)}

\subsubsection{Trend Particulate Matter and Traffic Volume}

Buses and lorries were classified into heavy class vehicles. As expected, this type of vehicle contributes to high particulate matter levels as it emits more gases compare to other types of vehicles. The numbers of heavy vehicles observed on October $16^{\text {th }}$ (weekend) was lower compared to data obtained on October $17^{\text {th }}$ (weekday). October $17^{\text {th }}$, Phase 1 (8.00 a.m. 9.00 a.m.) and Phase 2 (5.00 p.m. - 6.00 p.m.) recorded the highest data with 20 and 15 numbers of heavy vehicles respectively. From the observation, weekday data gives higher figures recorded compared to weekend. One possible explanation for this pattern is due to the tendency of people travelling more during the weekday compared to weekend.

On weekdays, heavy vehicles like buses are chosen to be the main medium of transportation by students and workers to school and workplace near the study area. Meanwhile, the numbers of lorries that travel at the study areas are more as these vehicles are often being used to transfer goods from one place to another. Therefore the numbers of heavy vehicles recorded on weekdays were higher than weekends.

Cars, vans and MPVs were classified into medium class vehicle. The difference of traffic volume pattern between both phases (Phase 1 and Phase 2) may be influenced by the 
working hours. Since morning session of school days start early and most companies start to operate at 8.30 a.m. or 9.00 a.m., some people tend to travel early in the morning in order to avoid heavy traffic. Some parents especially, choose to leave home early to send their children to school and will usually arrive at their workplace before the beginning of the working hours. During Phase 2, the traffic volume pattern was significantly steady with higher numbers of vehicles compared to Phase 1 as most people tend to leave their workplace, either to fetch their kids first or directly go back home or other places at the same time.

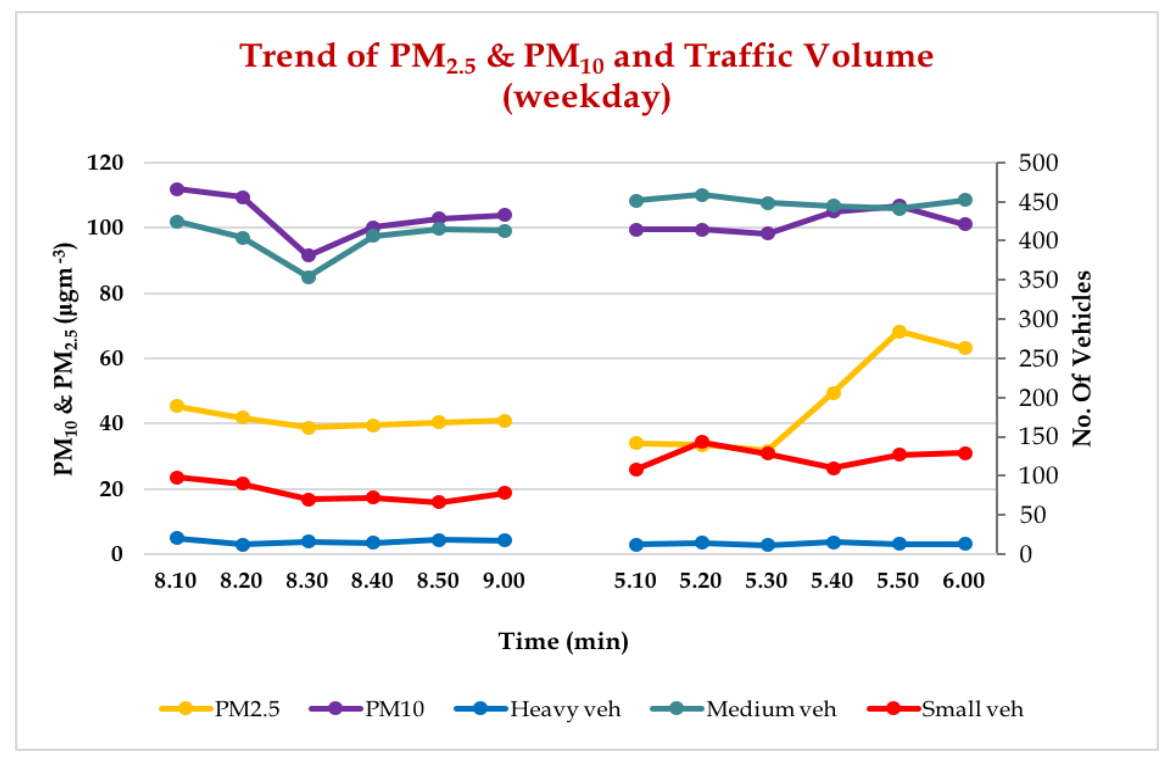

Fig. 3. Trend of $\mathrm{PM}_{2.5}$ and $\mathrm{PM}_{10}$ and traffic volume on weekday (residential area).

\subsubsection{Trend Particulate Matter and Wind Speed}

Data taken on October $17^{\text {th }}$ (weekday) shows the highest reading of wind speed both for Phase 1 and Phase 2 with $1.28 \mathrm{~ms}^{-1}$ and $1.55 \mathrm{~ms}^{-1}$ respectively.

Table 4. Wind Speed at Residential Area.

\begin{tabular}{|c|c|c|}
\hline \multirow{2}{*}{ Phase (time) } & \multicolumn{2}{|c|}{ Wind speed $\left(\mathbf{m s}^{-\mathbf{1}}\right)$} \\
\cline { 2 - 3 } & $\begin{array}{c}17^{\text {th }} \text { October } 2016 \\
\text { (Weekday) }\end{array}$ & $\begin{array}{c}16^{\text {th }} \text { October } 2016 \\
\text { (Weekend) }\end{array}$ \\
\hline $\begin{array}{c}\text { Phase } 1 \\
\text { (8.00 a.m. - } 9.00 \text { a.m.) }\end{array}$ & 1.28 & 0.82 \\
\hline $\begin{array}{c}\text { Phase } 2 \\
\text { (5.00 p.m. }-6.00 \text { p.m.) }\end{array}$ & 1.55 & 0.99 \\
\hline
\end{tabular}

From the graph, it was observed that particulate matter $\left(\mathrm{PM}_{2.5}\right.$ and $\left.\mathrm{PM}_{10}\right)$ and wind speed show similar trend patterns. The increase in wind speed values influenced the travel pattern of particulate matter. 


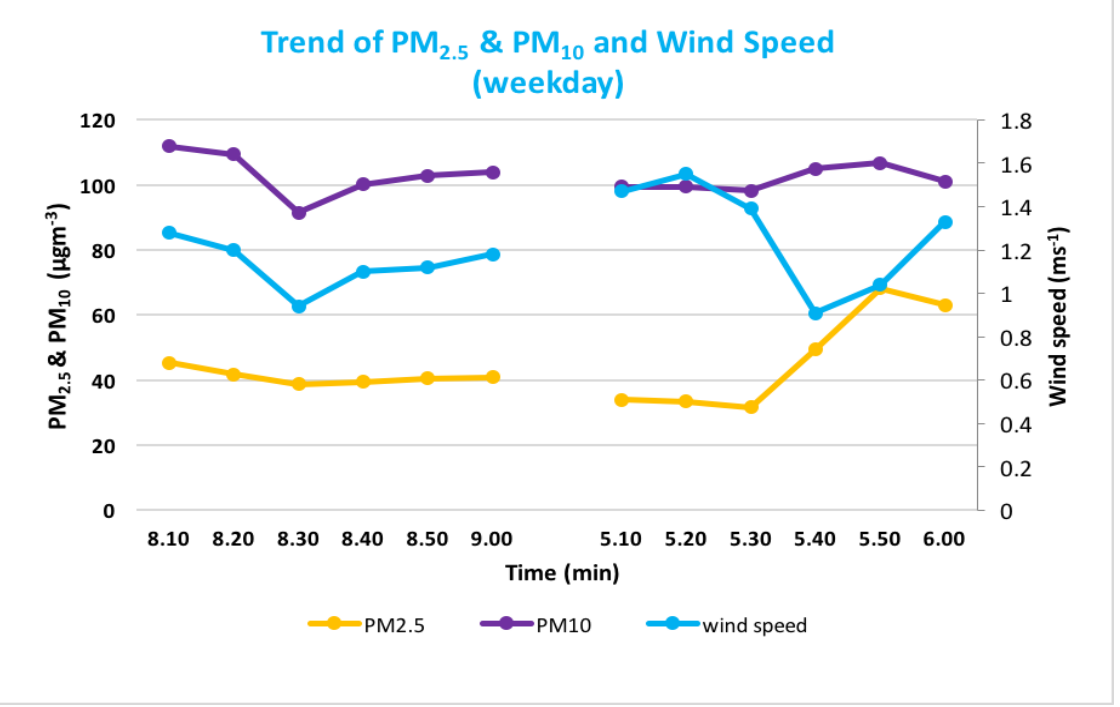

Fig. 4. Trend of $\mathrm{PM}_{2.5}$ and $\mathrm{PM}_{10}$ and wind speed on weekday (residential area).

\subsubsection{Trend Particulate Matter and Temperature}

Temperature observed on October $16^{\text {th }}$ (weekend) is lower compared to temperature obtained on October $17^{\text {th }}$ (weekday). Normally, the lower temperature gives higher wind speed value. Therefore, this indirectly contributes to the rise of travel pattern of particulate matter. Based on this study, the lowest temperature recorded was obtained during Phase 1 on October $16^{\text {th }}$ (weekend) with $28.10^{\circ} \mathrm{C}$. Phase 2 recorded highest temperature with 30.16 ${ }^{\circ} \mathrm{C}$ on October $17^{\text {th }}$ (weekday).

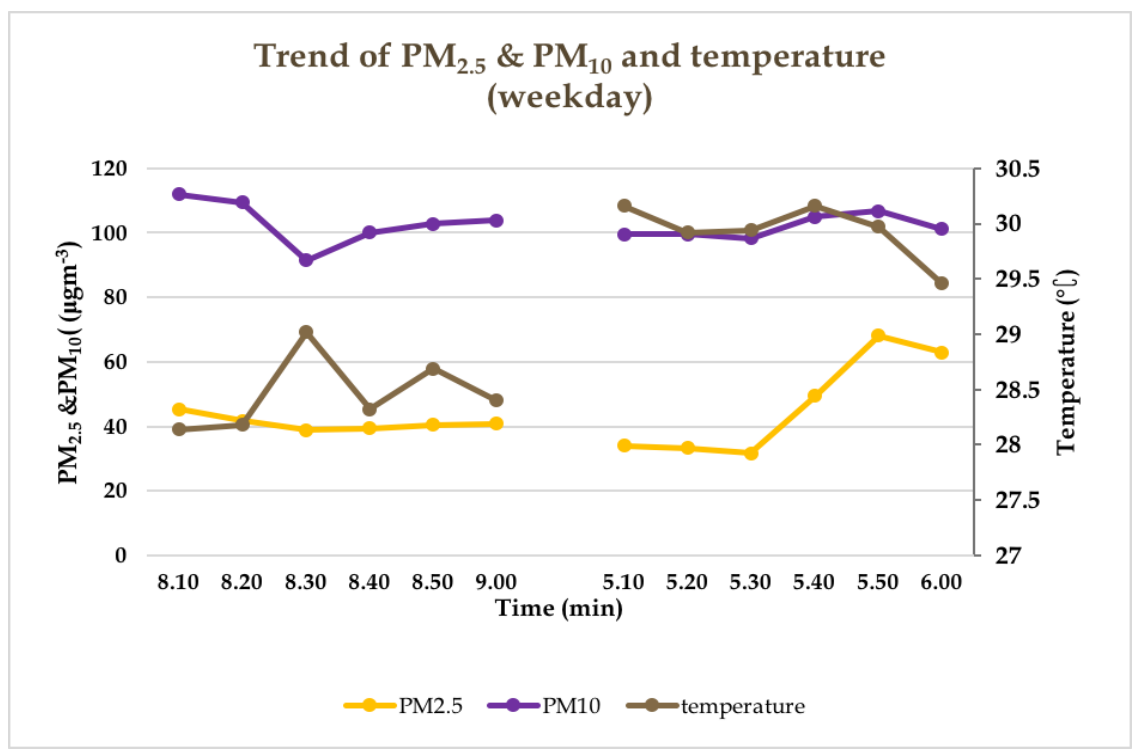

Fig. 5. Trend of $\mathrm{PM}_{2.5}$ and $\mathrm{PM}_{10}$ and temperature on weekday (residential area). 
From the graph, it was observed that particulate matter $\left(\mathrm{PM}_{2.5}\right.$ and $\left.\mathrm{PM}_{10}\right)$ and temperature shows contradictory profile patterns. Hence, we can conclude that temperature does effect particulate matter.

\subsubsection{Educational Area (near University of Selangor, UNISEL Seksyen 7)}

\subsubsection{Trend Particulate Matter and Traffic Volume}

During the 1-hour interval data collection, Phase 1 (8.00 a.m. - 9 a.m.) recorded the highest number of heavy vehicles with 16 numbers on October $12^{\text {th }}$ (weekday). For Phase 2 (5.00 p.m. -6 p.m.), Both weekday (October $12^{\text {th }}$ ) and weekend (October $15^{\text {th }}$ ) recorded highest data with 14 numbers of heavy vehicles passing by the study location. From the observation, weekday data gives highest data recorded compare to weekend. Moreover, the number of buses passing through the road near University of Selangor, UNISEL was higher compared to the number of lorries. This is due to the fact that the study area is nearby the university where many students chose bus as their main medium of transportation on a daily basis. The workers who need to go to work on weekdays may also contribute to the frequent number of buses passing by.

For the medium vehicles class, data observed on October $12^{\text {th }}$ (weekday) is higher compared to the data obtained on October $15^{\text {th }}$ (weekend) for both Phase 1 and Phase 2. During morning peak hour (Phase 1), data taken on October $12^{\text {th }}$ recorded 426 numbers while for Phase 2, highest data recorded with 489 numbers of medium vehicles. As for small vehicles, motorcycles and bicycles are classified into this class. There were only 2 bicycles passing through the road near UNISEL during the observation while the rest were motorcycles. The highest data recorded for this class was on October $12^{\text {th }}$ (weekday) with 108 and 128 numbers of vehicles for Phase 1 and Phase 2 respectively.

From the graph, it was observed that the particulate matter $\left(\mathrm{PM}_{2.5}\right.$ and $\left.\mathrm{PM}_{10}\right)$ and different classes of vehicles shows a similar trend. Thus, we can simply say that the increase in traffic volume contributes to the increase in the level of particulate matter. 


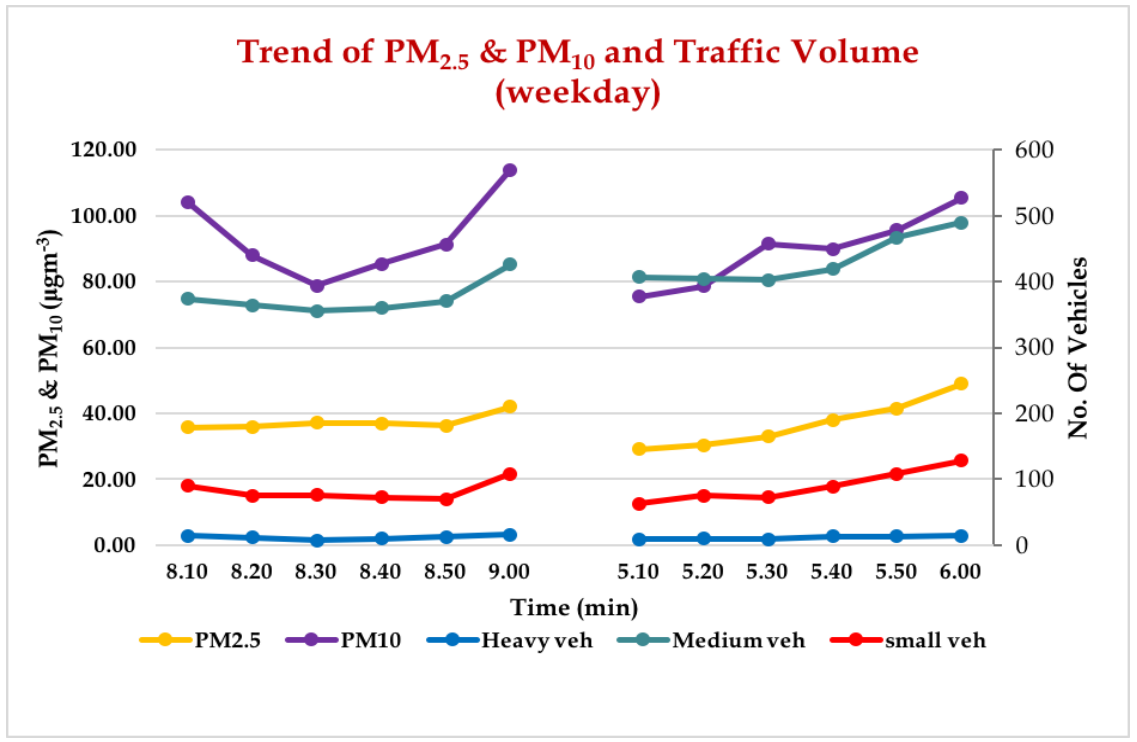

Fig. 6. Trend of $\mathrm{PM}_{2.5}$ and $\mathrm{PM}_{10}$ and traffic volume on weekday (educational area).

\subsubsection{Trend Particulate Matter and Wind Speed}

Despite the higher number of vehicles recorded at educational area on weekday, data recorded on October $15^{\text {th }}$ (weekend) shows highest wind speed value with $1.10 \mathrm{~ms}^{-1}$ during morning peak hour (Phase 1) while Phase 2 recorded $1.34 \mathrm{~ms}^{-1}$.

Table 5. Wind Speed at Educational Area.

\begin{tabular}{|c|c|c|}
\hline \multirow{2}{*}{ Phase (time) } & \multicolumn{2}{|c|}{ Wind speed $\left(\mathbf{m s}^{-\mathbf{1}}\right)$} \\
\cline { 2 - 3 } & $\begin{array}{c}12^{\text {th }} \text { October } 2016 \\
\text { (Weekday) }\end{array}$ & $\begin{array}{c}15^{\text {th }} \text { October 2016 } \\
\text { (Weekend) }\end{array}$ \\
\hline $\begin{array}{c}\text { Phase } 1 \\
\text { (8.00 a.m. }-9.00 \text { a.m.) }\end{array}$ & 0.62 & 1.10 \\
\hline $\begin{array}{c}\text { Phase } 2 \\
\text { (5.00 p.m. }-6.00 \text { p.m.) }\end{array}$ & 0.67 & 1.34 \\
\hline
\end{tabular}




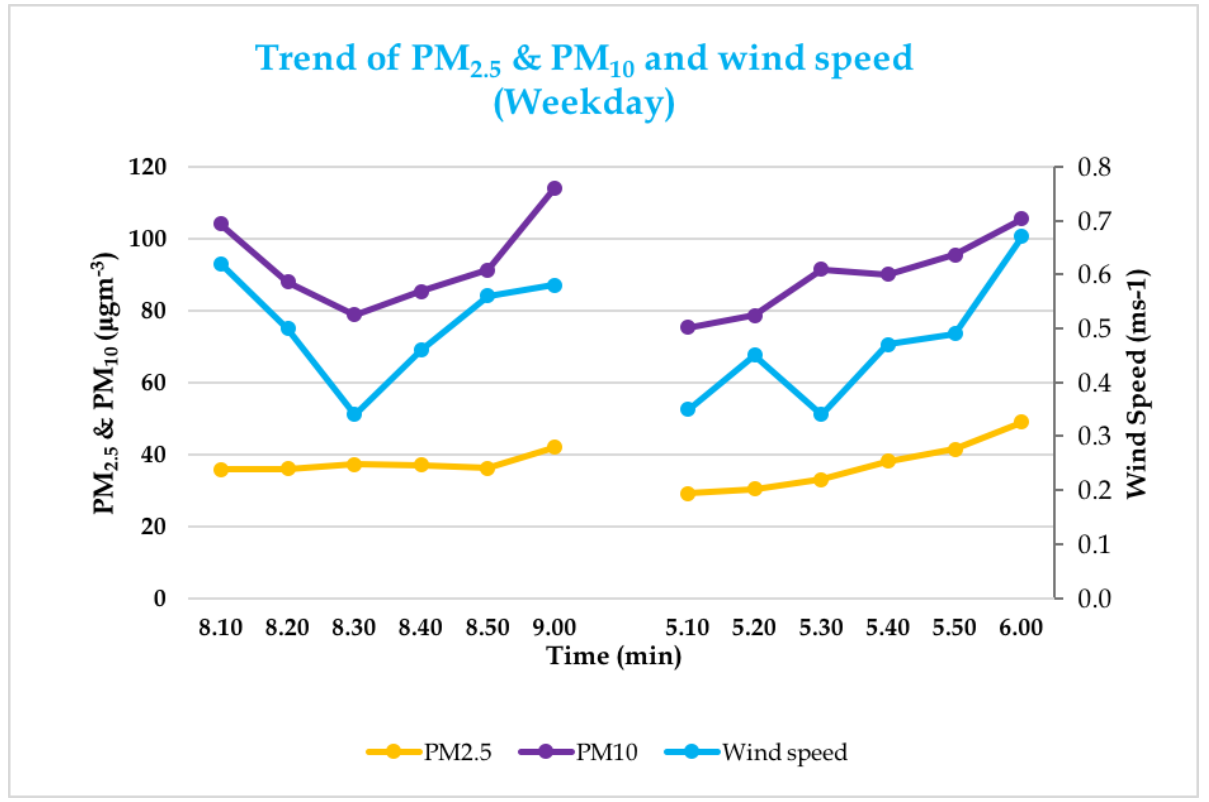

Fig. 7. Trend of $\mathrm{PM}_{2.5}$ and $\mathrm{PM}_{10}$ and wind speed on weekday (educational area).

From this particular graph, it was observed that the particulate matter $\left(\mathrm{PM}_{2.5}\right.$ and $\left.\mathrm{PM}_{10}\right)$ and wind speed shows a similar trend. Thus, the increase in wind speed values influenced the travel pattern of particulate matter.

\subsubsection{Trend Particulate Matter and Temperature}

From the observations, Phase 1 (8.00 a.m. -9 a.m.) recorded the lowest temperature at educational area with $26.50{ }^{\circ} \mathrm{C}$ on October $12^{\text {th }}$ (weekday) while the highest temperature was obtained in the evening (Phase 2) on the same day with $30.83{ }^{\circ} \mathrm{C}$. From the graph, it was observed that the particulate matter $\left(\mathrm{PM}_{2.5}\right.$ and $\left.\mathrm{PM}_{10}\right)$ and temperature does show contrary profile patterns. Hence, we can conclude that temperature does effect particulate matter. 


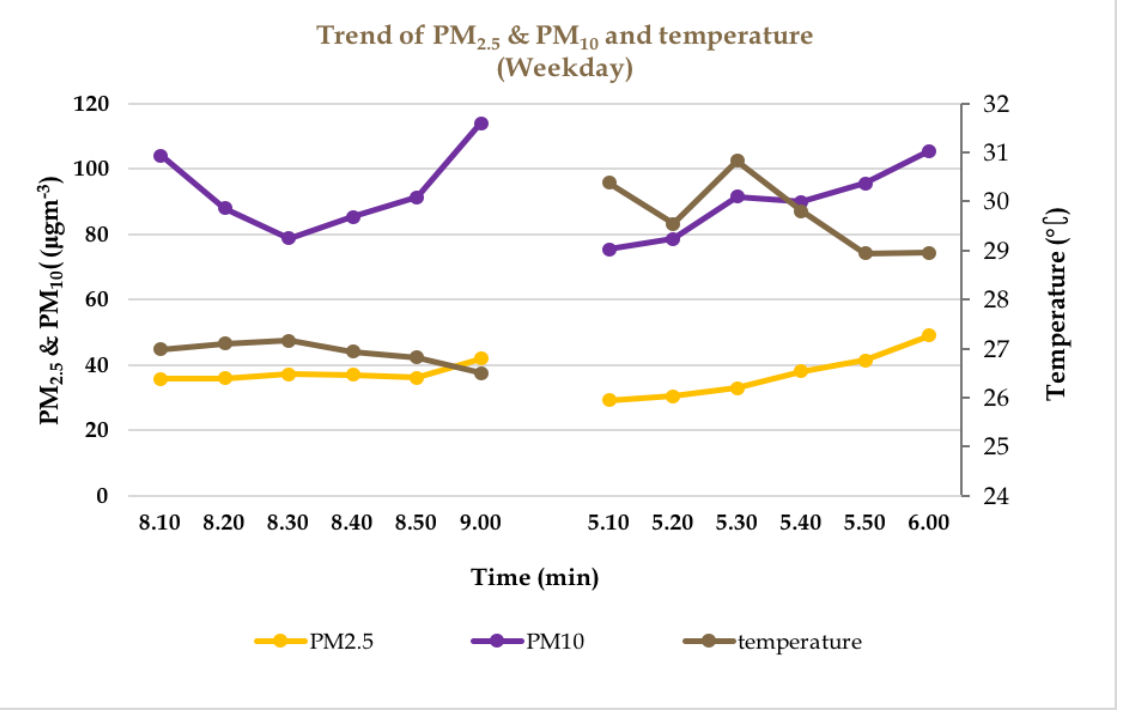

Fig. 8. Trend of $\mathrm{PM}_{2.5}$ and $\mathrm{PM}_{10}$ and temperature on weekday (educational area).

\subsection{Relationship Between Particulate Matter With Traffic Volume, Temperature And Wind Speed by using Statistical Package for Social Science (SPSS)}

The relationship between particulate matter and parameters (wind speed, temperature and traffic volume) was statistically analyzed by employing correlation analysis. Relationship between particulate matter and different classes of vehicles was represented by the corresponding Pearson correlation coefficients. Factors significant at $99 \%$ and $95 \%$ levels were marked as $* *$ and $*$ respectively. The results of correlation analysis are presented in Table 6.

Table 6. Summary on correlations among parameters for residential and educational areas.

\begin{tabular}{|c|c|c|c|c|c|c|c|c|c|}
\hline & Time & $\begin{array}{l}\text { Phase } \\
1 \text { or } 2\end{array}$ & $\mathrm{PM}_{2.5}$ & $\mathrm{PM}_{10}$ & $\begin{array}{l}\text { Wind } \\
\text { speed }\end{array}$ & $\begin{array}{l}\text { Tempe } \\
\text {-rature }\end{array}$ & $\begin{array}{l}\text { Heavy } \\
\text { veh. }\end{array}$ & $\begin{array}{l}\text { Mediu } \\
\text { m veh. }\end{array}$ & $\begin{array}{c}\text { Small } \\
\text { veh. }\end{array}$ \\
\hline \multicolumn{10}{|c|}{ Residential Area (Flat Nilam Sari) } \\
\hline Time & - & $.869^{* *}$ & $.495 * *$ & - & - & $.756^{* *}$ & - & $.807 * *$ & $.805^{* *}$ \\
\hline $\begin{array}{c}\text { Phase } \\
\text { (1 or } 2)\end{array}$ & $.869 * *$ & - & - & - & - & $.910 * *$ & - & $.768 * *$ & $.871^{* *}$ \\
\hline $\mathrm{PM}_{2.5}$ & $.495^{*}$ & - & - & $.762 * *$ & - & - & - & $.480 *$ & - \\
\hline $\mathrm{PM}_{10}$ & - & - & $.762 * *$ & - & - & - & - & $.439 *$ & - \\
\hline $\begin{array}{l}\text { Wind } \\
\text { speed }\end{array}$ & - & - & - & - & - & - & $.744 * *$ & - & - \\
\hline $\begin{array}{c}\text { Tempera } \\
\text {-ture }\end{array}$ & $.756^{* * *}$ & $.910 * *$ & - & - & - & - & - & $.594 * *$ & $.755^{* * *}$ \\
\hline $\begin{array}{c}\text { Heavy } \\
\text { vehicle }\end{array}$ & - & - & - & - & $.744 * *$ & - & - & - & - \\
\hline $\begin{array}{l}\text { Medium } \\
\text { vehicle }\end{array}$ & $.807 * *$ & $.768^{* * *}$ & $.480 *$ & $.439 *$ & - & $.594 * *$ & - & - & $.852 * *$ \\
\hline
\end{tabular}




\begin{tabular}{|c|c|c|c|c|c|c|c|c|c|}
\hline $\begin{array}{c}\text { Small } \\
\text { vehicle }\end{array}$ & $.805^{* *}$ & $.871 * *$ & - & - & - & $.755^{* *}$ & - & $.852 * *$ & - \\
\hline \multicolumn{10}{|c|}{ Educational Area (UNISEL) } \\
\hline Time & - & $.869 * *$ & $.602 * *$ & - & - & $.773 * *$ & - & $.796 * *$ & $.673 * *$ \\
\hline $\begin{array}{l}\text { Phase } \\
\text { (1 or } 2)\end{array}$ & $.869 * *$ & - & $.446^{*}$ & - & - & $.959 * *$ & - & $.764 * *$ & $.577 * *$ \\
\hline $\mathrm{PM}_{2.5}$ & $.602 * *$ & $.446^{*}$ & - & - & - & - & $.652 * *$ & $.783 * *$ & $.910 * *$ \\
\hline $\mathrm{PM}_{10}$ & - & - & - & - & - & - & - & - & - \\
\hline $\begin{array}{l}\text { Wind } \\
\text { speed }\end{array}$ & - & - & - & - & - & - & - & - & - \\
\hline $\begin{array}{c}\text { Tempera } \\
\text {-ture }\end{array}$ & $.773 * *$ & $.959 * *$ & - & - & - & - & - & $.636 * *$ & - \\
\hline $\begin{array}{l}\text { Heavy } \\
\text { vehicle }\end{array}$ & - & - & $.652 * *$ & - & - & - & - & $.626^{* * *}$ & $.651 * *$ \\
\hline $\begin{array}{l}\text { Medium } \\
\text { vehicle }\end{array}$ & $.796^{* *}$ & $.764 * *$ & $.783 * *$ & - & - & $.636 * *$ & $.626^{* *}$ & - & $.841 * *$ \\
\hline $\begin{array}{c}\text { Small } \\
\text { vehicle }\end{array}$ & $.673 * *$ & $.577^{*}$ & $.910 * *$ & - & - & - & $.651 * *$ & $.841 * *$ & - \\
\hline
\end{tabular}

$* *$ Correlation is significant at the 0.01 level (2-tailed)

* Correlation is significant at the 0.05 level (2-tailed)

Based on the correlation analysis for residential area, only 1 out of 3 classes of vehicles have a correlation with both particulate matters $\left(\mathrm{PM}_{2.5}\right.$ and $\left.\mathrm{PM}_{10}\right)$ which was medium vehicles. Medium class of vehicles was found to have correlation with both $\mathrm{PM}_{2.5}$ and $\mathrm{PM}_{10}$ at $95 \%$ significant level with Pearson correlation of .480 and .439 respectively. The other types of vehicles do not have any correlation with $\mathrm{PM}_{2.5}$ and $\mathrm{PM}_{10}$. Moreover, from the correlation analysis, it is also shown that wind speed and temperature do not have any correlation with both particulate matters $\left(\mathrm{PM}_{2.5}\right.$ and $\left.\mathrm{PM}_{10}\right)$.

For educational area, all types of vehicles (heavy, medium and small) were found to have correlation with $\mathrm{PM}_{2.5}$. The highest correlation was found between small vehicles and $\mathrm{PM}_{2.5}$ at $99 \%$ significant level with Pearson correlation of .910 . The other classes of vehicles (medium and heavy) were found to have correlation with $\mathrm{PM}_{2.5}$ at $99 \%$ significant level with Pearson correlation of .783 and .652 respectively. However, $\mathrm{PM}_{10}$ does not have any correlation with any classes of vehicles. Moreover, both particulate matters $\left(\mathrm{PM}_{2.5}\right.$ and $\mathrm{PM}_{10}$ ) do not have any correlation with wind speed and temperature.

Table 7. Correlation analysis between particulate matter $\left(\mathrm{PM}_{2.5}\right.$ and $\left.\mathrm{PM}_{10}\right)$ and parameters.

\begin{tabular}{|c|c|c|c|c|c|}
\hline & $\begin{array}{c}\text { Wind } \\
\text { Speed }\end{array}$ & $\begin{array}{c}\text { Temperat } \\
\text {-ure }\end{array}$ & $\begin{array}{c}\text { Heavy } \\
\text { Vehicles }\end{array}$ & $\begin{array}{c}\text { Medium } \\
\text { Vehicles }\end{array}$ & $\begin{array}{c}\text { Small } \\
\text { Vehicles }\end{array}$ \\
\hline \multicolumn{7}{|c|}{ Residential Area (Flat Nilam Sari) } \\
\hline $\mathrm{PM}_{2.5}$ & - & - & - & $.480^{*}$ & - \\
\hline $\mathrm{PM}_{10}$ & - & - & - & $.439^{*}$ & - \\
\hline \multicolumn{7}{|c|}{ Educational Area (UNISEL) } \\
\hline $\mathrm{PM}_{2.5}$ & - & - & $.652^{* *}$ & $.783^{* *}$ & $.910^{* *}$ \\
\hline $\mathrm{PM}_{10}$ & - & - & - & - & - \\
\hline
\end{tabular}




\section{Conclusion}

According to [25], Malaysian Ambient Air Quality Guidelines (MAAQS) has provided permissible limit for $\mathrm{PM}_{2.5}$ and $\mathrm{PM}_{10}$ for a 24-hour average with $75 \mu \mathrm{gm}^{-3}$ and $150 \mu \mathrm{gm}^{-3}$ respectively. From the data analysis, it was found that the particulate matter for both $\mathrm{PM}_{2.5}$ and $\mathrm{PM}_{10}$ at both locations does not exceed the permissible limit provided by MAAQS. For residential area, the range of particulate matter of $\mathrm{PM}_{2.5}$ obtained is between $43.86 \mu \mathrm{gm}^{-3}$ and $40.25 \mu \mathrm{gm}^{-3}$, while the range of particulate matter of $\mathrm{PM}_{10}$ is between $101.83 \mu \mathrm{gm}^{-3}$ and $102.47 \mu \mathrm{gm}^{-3}$. For educational area, the range of particulate matter for $\mathrm{PM}_{2.5}$ and $\mathrm{PM}_{10}$ are from $37.1 \mu \mathrm{gm}^{-3}$ to $35.2 \mu \mathrm{gm}^{-3}$ and from $91.5 \mu \mathrm{gm}^{-3}$ to $80.2 \mu \mathrm{gm}^{-3}$ respectively.

Based on the traffic volume at the residential area, the correlations were found only between particulate matters $\left(\mathrm{PM}_{2.5}\right.$ and $\left.\mathrm{PM}_{10}\right)$ with medium vehicles that had a significant level with Pearson correlation at $95 \%$ that are .480 and .439 respectively. However, for educational area, there were many correlations found. The relationship obtained between $\mathrm{PM}_{2.5}$ with all types of vehicles having a significant level at $99 \%$. The highest correlation was obtained between small vehicles and $\mathrm{PM}_{2.5}$ was at significant level of $99 \%$ with .910 Pearson's coefficient. Nevertheless, for wind speed and temperature, both study areas did not have any relationship between all particulate matters $\left(\mathrm{PM}_{2.5}\right.$ and $\left.\mathrm{PM}_{10}\right)$. Based on these correlation analyses, only the high traffic volumes significantly contribute to the increase amount of particulate matters in this study.

The air quality index (AQI) reading of $\mathrm{PM}_{2.5}$ and $\mathrm{PM}_{10}$ at residential area were recorded higher compared to educational area. However, for both study areas, the AQI for $\mathrm{PM}_{2.5}$ was categorized as unhealthy while for $\mathrm{PM}_{10}$, the $\mathrm{AQI}$ was categorized as moderate. Nevertheless, the finer particles $\left(\mathrm{PM}_{2.5}\right)$ are more hazardous to health compared to coarser particles $\left(\mathrm{PM}_{10}\right)$. Thus, measures are required to be taken to overcome this problem. Particulate matter was produced from traffic vehicles and has significant correlation with the increase of travelled particles. The usage of heavy and medium vehicles such as lorries and cars need to be controlled, so the road capacity will not be exceeded and therefore, reducing particulate matters. This monitoring study is crucial in order to assist responsible parties to take all possible actions in ensuring the level of particulate matters at residential and educational areas are controlled and always be the best place to live and learn.

\section{References}

1. E. D. Enger, B. F. Smith, Q. Rev. Bio. 77, 92 (2000)

2. M. L. Davis, D. Cornwell, Introduction to Environmental Engineering (McGraw-Hill 2013)

3. B. Brunekreef, S. T. Holgate, Lancet 360, 1233-1242 (2002)

4. D. Mage, G. Ozolins, P. Peterson, A. Webster, R. Orthofer, V. Vandeweerd, M. Gwynne, Atmos. Environ. 30, 681-686 (1996)

5. C. J. Saitanis, M. G. Karandinos, Chemosphere 44, 813-821 (2001)

6. USEPA, Air Quality Index (Research Triangle Park, North Carolina, EPA, 2014)

7. WHO, Air Quality Guidelines for Europe (Copenhagen, 2000)

8. X. Xu, L. Wang, Am. Rev. Respir. Dis. 148, 1516-1522 (1993)

9. R. McConnell, K. Berhane, F. Gilliland, S. J. London, T. Islam, W. J. Gauderman, E. Avol, H. G. Margolis, J. M. Peters, Lancet 359, 386-391 (2002)

10. I. Romieu, F. Meneses, S. Ruiz, J. J. Sienra, J. Huerta, M. C. White, R. A. Etzel, Am. J. Respir. Crit. Care Med. 154, 300-307 (1996)

11. W. P. Cunningham, M. A. Cunningham, Environmental Science: A Global Concern (Boston, McGraw Hill, 2004) 
12. D. W. Dockery, C. A. $3^{\text {rd }}$ Pope, X. Xu, J. D. Spengler, J. H. Ware, M. E. Fay, B. G. Jr Ferris, F. E. Speizer, N. Engl. J. Med. 329, 1753-1759 (1993)

13. X. Wang, H. Ding, L. Ryan, X. Xu, Environ. Health Perspect. 105, 514-520 (1997)

14. L. A. Pereira, D. Loomis, G. M. Conceicao, A. L. Braga, R. M. Arcas, H. S. Kishi, J. M. Singer, G. M. Bohm, P. H. Saldiva, Environ. Health Perspect. 106, 325-329 (1998)

15. D. A. Vallero, Fundamentals of Air Pollution (Elsevier, 2008)

16. DOE, Malaysia Environmental Quality Report (Department of the Environment, Ministry of Science, Technology and Environment, Malaysia, 1996)

17. N. Bukowiecki, J. Dommen, A. S. H. Prevot, R. Richter, E. Weingartner, U. Baltansperger, Atmos. Environ. 36, 5569-5579 (2002)

18. J. Fenger, Atmos. Environ. 33, 4877-4900 (1999)

19. DOE, Clean Air Regional Workshop - Fighting Urban Air Pollution: From Plan to Action, Department of the Environment (Ministry of Science, Technology and Environment, Malaysia, 2001)

20. R. Afroz, M. N. Hassan, N. A. Ibrahim, Environ. Res. 92, 71-77 (2003)

21. M. Krzyzanowski, B. Kuna-Dibbert, J. Schneider, Health Effects of Transport-related Air Pollution (Denmark, World Health Organization, 2005)

22. M. B. Awang, A. B. Jaafar, A. M. Abdullah, M. B. Ismail, M. N. Hassan, R. Abdullah, S. Johan, H. Noor, Respirology 5, 183-196 (2000)

23. J. T. V. d. Wal, L. H. J. M. Janssen, J. Aerosol Sci. 27, 681-682 (1996)

24. User Manual: DC1700 Air Quality Monitor (Dylos Corporation, 2900 Adams Street, C37, Riverside, CA, USA, 2012)

25. User Manual: Model 45158 Mini Thermo-Anemometer (FLIR Commercial Systems Inc., 9 Townsend West, Nashua, NH 03063, USA, 2013)

26. E. Diapouli, A. Chaloulakou, N. Spyrellis, Global NEST J. 10, 201-208 (2008)

27. DOE, New Malaysia Ambient Air Quality Standard (Department of the Environment, Ministry of Science, Technology and Environment, Malaysia, 2015)

28. N. Y. Y. Razali, M. T. Latif, D. Dominick, N. Mohamad, F. R. Sulaiman, T. Srithawirat, Build. Environ. 87, 108-116 (2015) 